Artículo científico

Volumen 32(3):963-982. Septiembre-diciembre, 2021 e-ISSN 2215-3608, doi:10.15517/am.v32i3.44473

https://revistas.ucr.ac.cr/index.php/agromeso/index

\title{
Dinámica de la producción y consumo de carne ovina en México 1970 a $2019^{1}$
}

\section{Lamb production and consumption dynamic in Mexico from 1970 to 2019}

\author{
Encarnación Ernesto Bobadilla-Soto², Fernando Ochoa-Ambriz ${ }^{3}$, Mauricio Perea-Peña ${ }^{3}$
}

1 Recepción: 9 de noviembre, 2020. Aceptación: 1 de marzo, 2021. Este trabajo formó parte del proyecto: "Fomento al desarrollo económico agropecuario para la producción de alimentos mediante agronegocios", a través de Cátedras CONACyT, México.

2 Consejo Nacional de Ciencia y Tecnología (CONACYT), Universidad Michoacana de San Nicolás de Hidalgo, Instituto de Investigaciones Agropecuarias y Forestales. Km 9.5 de la Carretera Morelia-Zinapécuaro, Michoacán, México. bosee03@hotmail.com (https://orcid. org/0000-0003-0738-0432).

3 Universidad Michoacana de San Nicolás de Hidalgo, Instituto de Investigaciones Agropecuarias y Forestales. Km 9.5 de la Carretera MoreliaZinapécuaro, Michoacán, México. fernando8a60@gmail.com (https://orcid.org/0000-0002-3817-2030); mapepe17@hotmail.com (autor para correspondencia; https://orcid.org/0000-0003-4718-1323).

\section{Resumen}

Introducción. El volumen de producción de carne de ovino en México no satisfizo la demanda, principalmente para la elaboración del platillo tradicional "barbacoa". Objetivo. Evaluar la dinámica de la producción y consumo de carne de ovinos en México. Materiales y métodos. La información estadística se obtuvo a partir de publicaciones oficiales de México del año 1970 al año 2019. Se determinaron los incrementos/decrementos, la tasa de crecimiento media anual, se calculó el índice estacional con el método de porcentajes promedios. Los datos de cada mes se expresaron como porcentajes del precio y de la producción. Resultados. La producción de carne en canal de ovino de 1970 a 2019 tuvo una tasa de crecimiento media anual de 2,2 \%, en 2019 la producción fue 64030 toneladas; la carne de ovino pagó mejor (USD por kg) en comparación con otras especies pecuarias. En 2019 los precios pagados fueron 1,47, 1,69, 1,54, 1,34 y 1,08 de ovinos (Ovis aries), bovinos (Bos taurus), caprinos (Capra hircus), porcinos (Sus scrofa) y pollos (Gallus gallus domesticus), respectivamente. El índice de estacionalidad para la producción de ovinos en pie, mostró que los meses de enero a mayo fue cuando se tuvo la menor producción $(<100)$ y de junio a diciembre se dio la mayor (>100). La variabilidad del índice de la estacionalidad de los precios en carne de ovinos fue de 99,1 hasta 100,7 \%, para este índice fue muy baja la variación (1,6\%), esto significó un precio estable todo el año; el consumo per cápita en México pasó de 467 a 567 g de 1970 a 2019. Conclusión. Existió una marcada estacionalidad en la producción; sin embargo, el precio se mantuvo constante a través del año, debido a que las importaciones estabilizaron el precio en la época de poca producción en México.

Palabras clave: precio, producción, estacionalidad, importaciones, consumo.

\section{Abstract}

Introduction. The volume of lamb meat production in Mexico did not satisfy the demand, mainly for the preparation of the traditional dish 'barbacoa'. Objective. To evaluate the dynamics of lamp meat production and 
consumption in Mexico. Materials and methods. The statistical information was obtained from Mexico's official publications from 1970 to 2019. Increases/decreases, the annual growth rate and the seasonal index calculated with the method of average percentages, were determined, the last one was calculated by the average percentage method. The data per month was shown as cost and production percentages. Results. The sheep carcass meat production from 1970 to 2019 had an average annual growth rate of 2,2 \%, in 2019 production was 64,030 tons; sheep meat paid better (USD per kg) compared to other livestock species. In 2019 the prices paid were 1.47, 1.69, 1.54, 1.34, and 1.08 for sheep (Ovis aries), cattle (Bos taurus), goats (Capra hircus), pigs (Sus scrofa) and chickens (Gallus gallus domesticus), respectively. The seasonality index for live sheep production showed that from January to May were when there was the lowest production $(<100)$, and from June to December the highest $(>100)$. The variability of the seasonality index of sheep meat prices were from 99.1 up to $100.7 \%$, for this index the variation was very low (1.6 $\%$ ), this meant a stable price all year round; the per capita consumption in Mexico went from 467 to $567 \mathrm{~g}$ from 1970 to 2019. Conclusion. There was a strong seasonality in production; however, the price remained constant throughout the year, due to the fact that imports stabilized the price in the low production season in Mexico.

Keywords: price, production, seasonality, imports, consumption.

\section{Introducción}

Los sistemas de producción de ovinos (Ovis aries) muestran grandes coincidencias en los distintos países subdesarrollados donde se desarrolla dicha actividad, en consideración a similitud de factores que determinan condiciones desfavorables orográfica y climática, que hacen uso de los terrenos más abruptos o áridos y, por lo tanto, menos aptos para otras actividades agropecuarias (Valerio et al., 2009). La mayoría de la ovinocultura en México es desarrollada bajo sistema extensivo, también denominado tradicional, donde su alimentación se basa en el pastoreo a orilla de caminos vecinales y pastizales en zonas de conservación. Aunque también se cuenta con sistemas de alimentación mixtos, los cuales disponen de forrajes, entre ellos la avena (Avena sativa) y ebo (Vicia sativa), que son producidos en las tierras de los productores ovinos (Herrera-Haro et al., 2019), también presentan diferente nivel tecnológico, capacidad productiva y uso de recursos (Espejel-García et al., 2015).

Un sistema productivo es un conjunto de elementos técnicos y humanos relacionados entre sí, que presenta distintos arreglos en uso de insumos, formas de manejo y relaciones de trabajo. La producción de ovinos opera bajo una de tres modalidades: intensivo, semi-intensivo o mixto y extensivo, también llamada ovinocultura social. En el primero, los animales se encuentran confinados en instalaciones tecnificadas (corrales, comederos y bebederos); se utilizan razas de alto rendimiento, insumos industriales y sistemas de sanidad, manejo de desechos, programas de nutrición y reproducción. El sistema mixto combina la agricultura con la crianza de animales, los cuales se alimentan de pastizales inducidos o cultivados, pastos ubicados en las orillas de caminos, esquilmos agrícolas, granos básicos (en su mayoría granos y rastrojo de maíz), alimentos elaborados por sus dueño/as y concentrados industriales en cantidades limitadas. Los animales son concebidos como un complemento a la nutrición familiar y la economía doméstica. Por último, en el sistema extensivo los animales pastorean en agostaderos naturales durante el día y se guardan en la noche, la alimentación se basa en lo que consumen en el pastoreo; la inversión de capital en alimentación, sanidad e infraestructura es mínima y la mano de obra es generalmente familiar (Améndola et al., 2005; Martínez-González et al., 2010; 2011). La problemática que aqueja a la ovinocultura es compleja, cuesta trabajo entender por qué si hay buen precio para todo lo derivado del ovino, hay demanda insatisfecha y mercados potenciales, es una actividad noble, generadora de empleos. Se puede señalar que de los problemas que aquejan a la ovinocultura nacional desde hace muchos años, se destaca la pobre eficiencia productiva de los rebaños; un somero análisis de las cifras muestra que si la población está en los 6,4 millones de animales y se sacrifican 2,1, 
ello indicaría que solo se sacrifica el 32,8 \% de la población, cuando en otros países rebasan el 50 \% (MartínezGonzález et al., 2010).

Los sistemas de producción de ovinos tradicionales compiten con grandes productores internacionales, debido a la política macroeconómica de apertura comercial vigente en México, adem’ås con la desventaja de estar produciendo en un contexto de políticas nacionales orientadas a la descentralización de las actividades de desarrollo y al impulso de aquellos productores rurales con potencial competitivo, lo cual determina que el mercado y las políticas tengan impacto sobre la competitividad de este sector (Díaz-Sánchez et al., 2018).

En México, los sistemas pastoriles tradicionales son los que abastecen de carne de ovino a los mercados locales (Espejel-García et al., 2015). En estos sistemas, los ovinos representan una alternativa rentable por el buen precio de venta del cordero y la alta demanda (Pérez-Hernández et al., 2011), la cual se cubre con importaciones (DíazSánchez et al., 2018).

El volumen de producción en México es deficitario, ya que las importaciones de carne de ovino fueron elevadas al principio de la década de los 2000, las cuales variaron en alrededor del $60 \%$ del consumo nacional. México se ha convertido en un país importador de carne de ovino (Bobadilla-Soto et al., 2017), principalmente de Australia, Nueva Zelandia, Canadá, Estados Unidos América (EUA) y Uruguay (Mondragón-Ancelmo et al., 2012).

La barbacoa es un platillo típico del centro de México (Estado de México, Hidalgo y Tlaxcala), aunque está difundida por todo el país; es el producto obtenido de la cocción de la carne en un hoyo u horno envuelta en pencas de maguey pulquero (Agave salmiana, Otto) y condimentos (Mondragón-Ancelmo et al., 2018). La preferencia del ganado nacional es por la frescura de la carne y la presencia de vísceras para la elaboración de la pancita, platillo elaborado con el estómago del borrego relleno con las vísceras de los ovinos, con chile de árbol (Capsicum annuиm L.) y epazote (Dysphania ambrosioides L.), todo cocido junto con la carne, a lo que le atribuyen rendimiento y sabor del producto (Molina-Cervantes, 2005).

El $95 \%$ del consumo de la carne de ovinos se utiliza para elaborar barbacoa y el resto en cortes finos (Mondragón-Ancelmo et al., 2012), por su parte, Molina-Cervantes (2005) reportó que el 98 \% de la de la carne de borrego que se produce en México o se importa fue destinado al mercado de la barbacoa.

En México existe una demanda insatisfecha de ovinos para su consumo, por cual sea convertido en un país importador para la elaboración del platillo tradicional conocido como barbacoa; por lo anterior, el objetivo de este trabajo fue evaluar la dinámica de la producción y consumo de carne de ovinos en México.

\section{Materiales y métodos}

La información estadística contenida en este trabajo pertenece a las publicaciones oficiales de México, del Sistema de Información Agroalimentaria y Pesquera (SIAP) y sus organismos sectoriales, de 1970 a 2019, de población, producción y precios pagados al productor. La información de las importaciones se obtuvo de la Organización de las Naciones Unidas para la Alimentación y la Agricultura (FAO) de 1980 a 2019. Las fracciones arancelarias que se utilizaron para obtener la estacionalidad de las importaciones de ovinos (Ovis aries) en pie (animal vivo para engorda o ser sacrificado) y de carne, se muestran en el Cuadro 1, de enero 2003 a diciembre 2019, a través del Sistema de Información Arancelaria Vía Internet (SIAVI), que depende de la Secretaría de Economía de México.

La información de los precios de ovinos en pie pagados al productor y de carne en canal (parte del cuerpo de los animales sacrificados, después debe retirárseles la piel, cabeza, las vísceras con sus contenidos, la sangre y la parte distal de los miembros), se obtuvo del Sistema Nacional de Información e Integración de Mercados (SNIIM) para la serie enero del 2003 a diciembre de 2019; dado que se contaba con datos diarios, se sacaron los promedios de los precios de cada mes. Los precios de los ovinos y carne se deflactaron con el Índice Nacional de Precios al Consumo (INPC) de la segunda quincena de julio del 2018, para pasarlo a pesos constantes. 
Cuadro 1. Fracciones arancelarias de México para ovinos (Ovis aries) en pie (animal vivo para engorda o ser sacrificado) y carne. Enero 2003 a diciembre 2019.

Table 1. Mexican tariff fractions for live (live animal to be feedlot or slaughtered) sheep (Ovis aries) and meat. January 2003 to December 2019.

\begin{tabular}{ll}
\hline Fracción* & Descripción \\
\hline 01041002 & Para abasto \\
01041099 & Los de más \\
01041001 & Con pedigree o certificado de alto registro \\
02041001 & Canales o medias canales de cordero fresca o refrigerada \\
02042101 & Canales o medias canales (carne de ovino, fresca o congelada) \\
02042299 & Los demás cortes (trozos) sin deshuesar (carne de ovino, fresca o refrigerada) \\
02042301 & Deshuesada (carne de ovino, fresca o refrigerada) \\
02043001 & Canales o medias canales de cordero congelado \\
02044101 & En canales o medias canales (carne de ovino congelada) \\
02044299 & Los demás cortes (trozos) sin deshuesar \\
02044301 & Deshuesada (carne de ovino congelada) \\
\hline
\end{tabular}

* Sistema de Información Arancelaria Vía Internet [SIAVI] (2021), Secretaría de Economía (2021).

Se determinaron los incrementos/decrementos, la tasa de crecimiento media anual (TCMA) para población, producción, precios de ovinos en pie y carne en canal, exportaciones e importaciones. Los datos se ajustaron por el método de los cuadrados mínimos para obtener la tendencia (Barrera-Islas \& Chalita-Tovar, 2015; Martínez, 1982), en todos los casos. El consumo nacional aparente que se obtuvo fue igual a: producción nacional más importaciones, menos exportaciones y el consumo per cápita, este último fue igual a: el consumo nacional aparente entre el número de habitantes.

Para calcular el índice estacional se utilizó el método de porcentajes promedios, los datos de cada mes se expresaron como porcentajes del precio y de producción promedio del año respectivo.

Los porcentajes del mismo mes de los diferentes años se promediaron y se obtuvo un porcentaje o un índice estacional para ese mes. Los doce porcentajes resultantes en el año conformaron el índice estacional. Se graficaron y se tomó como base un índice de cien, con la finalidad de hacer más explícitas las variaciones durante el transcurso del año del precio y de la producción. En los meses que el índice superó el $100 \%$, significó que los precios fueron superiores al promedio anual; cuando el índice estuvo por debajo de la línea del $100 \%$, los precios para ese mes están por debajo del promedio anual (Hanke \& Reitsch, 1997; Rouco-Yañez \& Muñoz-Luna, 2006; Troncoso \& Lobos, 2004). Dicho índice se determina con el método de porcentaje medio, que consiste en dividirle a la serie original la media anual, matemáticamente se expone en la ecuación 1:

$\mathrm{IE}=\sum \mathrm{M}$

Donde:

$\mathrm{IE}=$ índice estacional.

$\mathrm{M}=$ promedio del mes (ecuación 1.1).

$\mathrm{M}=\left(\mathrm{x}_{\mathrm{i}} /\left(\sum \mathrm{x}_{\mathrm{i}} / \mathrm{n}\right)\right)(100)$ (ecuación 1)

(ecuación 1.1) 
Donde:

$\mathrm{x}_{\mathrm{i}}=$ mes de referencia.

$\mathrm{n}=$ número de años.

La estacionalidad se elimina entonces dividiendo los valores originales entre su respectivo índice (ecuación 1.2):

$\mathrm{S}=\mathrm{VO} / \mathrm{IE}$

(ecuación 1.2)

Donde:

$\mathrm{S}=$ componente estacional.

$\mathrm{VO}=$ valores originales

$\mathrm{IE}=$ Índice estacional.

Si se sustituye el resultado de (13) en la ecuación general (1) la expresión matemática general es la ecuación 2:

$\mathrm{Yt} 1=\mathrm{Yt} / \mathrm{S}=(\mathrm{T})(\mathrm{C})(\mathrm{I})$

(ecuación 2)

Donde:

Yt1 = variable respuesta sin componente estacional (precio y producción). Resto de variables ídem ecuación (1).

Cada uno de los datos sin estacionalidad Yt1 de la ecuación (2) se ajustaron con sus correspondientes de tendencia (1.1) y (1.2), se obtuvo un cociente expresado en porcentaje, se eliminó así el componente de tendencia de la ecuación general y se logró la nueva ecuación 3 que contiene los componentes cíclicos e irregulares, en:

$\mathrm{Yt} 2=\mathrm{Yt} 1 / \mathrm{T}=(\mathrm{C})(\mathrm{I}) \quad$ (ecuación 3)

Donde:

Yt2 = variable de respuesta sin componente estacional ni de tendencia (precio y producción). Resto de variables ídem ecuación (1).

Se sustituyeron los componentes las ecuaciones 3 y 1.1, 1.2, el cálculo se realizó de la siguiente forma (ecuación 3.1):

$\mathrm{VCI}=((\mathrm{MSD} / \mathrm{MST}))(100)$

(ecuación 3.1)

Donde:

$\mathrm{VCI}=$ variaciones cíclicas e irregulares.

MSD $=$ mes sin componente estacional.

MST $=$ mes sin componente de tendencia .

\section{Resultados}

\section{Producción nacional}

La población de ovinos pasó de 6,1 millones en 1970 a 8,7 millones en 2019, con una tasa de crecimiento medio anual (TCMA) de 0,71 \%, con un incremento en cincuenta años de 2,6 millones de cabezas, el año de 1985 
se presentó la menor población con 5,7 millones. La producción de carne de ovino pasó de 20780 a 64030 t en el periodo de 1970 a 2019, con una TCMA de 2,28 \%, y un incremento total de 43251 t (Figura 1).

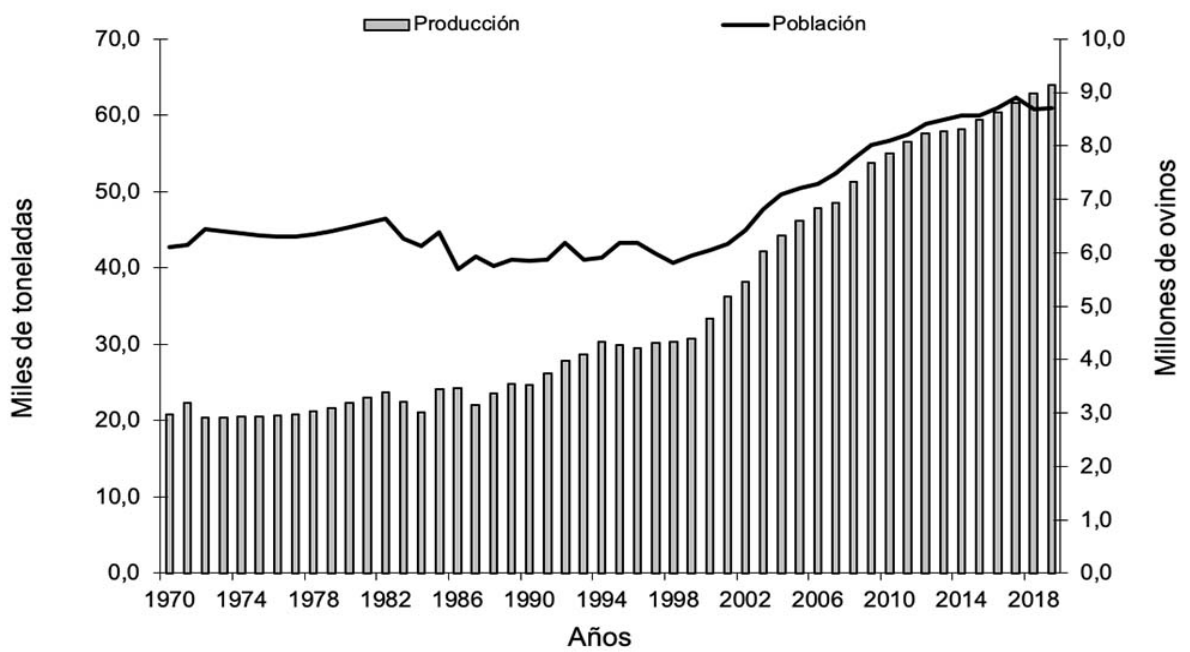

Figura 1. Población ovina (Ovis aries) y producción de carne de ovinos en canal desde 1970-2019 en México. Fuente: elaborado con datos de Sistema de Información Agroalimentaria y Pesquera [SIAP] (2021).

Figure 1. Sheep population (Ovis aries) and sheep meat carcass production from 1970 to 2019 in Mexico. Source: Developed with SIAP (2021) data.

Los principales estados productores de carne de ovinos en canal en el 2019 fueron el Estado de México con una aportación del 14,5 \% con 9289 t, le siguieron los estados de Hidalgo, Veracruz, Zacatecas, Jalisco y Puebla con $6770,5425,4279,4536$ y $4401 \mathrm{t}$, respectivamente (Figura 2).

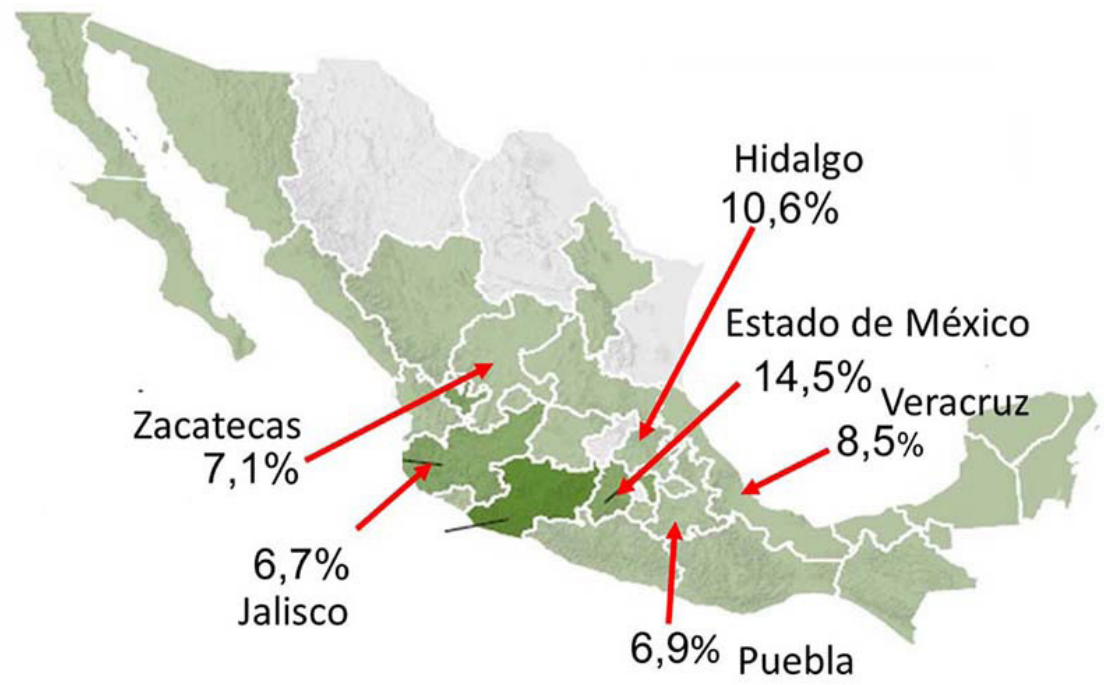

Figura 2. Participación por estado en la producción carne en canal de ovinos (Ovis aries). México, 2019.

Figure 2. State participation in sheep meat carcass (Ovis aries) production. Mexico 2019. 


\section{Producción por regiones}

Las cinco regiones socioeconómicas en que se divide México y los estados que las componen se muestran en el Cuadro 2. La región Centro, donde se ubican los estados de México, Hidalgo y Puebla, en 2019, fue la de mayor producción de ovinos en pie con el 38,7 \% y una producción de 46428 t. La región Centro occidente, aportó el $27,4 \%$, equivalente a 32811 t y los estados con mayor participación fueron Jalisco y Zacatecas; en tercer lugar, se encontró el Sur sureste con el 21,8 \% que correspondió a 26145 t, donde el estado de Veracruz fue el que tuvo la mayor participación en esta región.

Cuadro 2. Regiones socioeconómicas de México y estados que la componen. México. 2019.

Table 2. Mexico's socioeconomic regions and states that form it. Mexico. 2019.

\begin{tabular}{ll}
\hline Región & Estado \\
\hline Centro & Ciudad de México, Estado de México, Hidalgo, Morelos, Puebla y Tlaxcala \\
Centro occidente & Aguascalientes, Colima, Guanajuato, Jalisco, Michoacán, Nayarit, Querétaro, San Luís Potosí y Zacatecas \\
Sur sureste & Campeche, Chiapas, Guerrero, Oaxaca, Quintana Roo, Tabasco, Veracruz y Yucatán. \\
Noroeste & Baja California, Baja California Sur, Sonora y Sinaloa \\
Noreste & Chihuahua, Coahuila, Durango, Nuevo León y Tamaulipas \\
\hline
\end{tabular}

Fuente / Source: Secretaria de Economía (2021).

Para el año de 1980, la producción de carne en canal de ovinos en la región centro occidente era la que aportaba mayor producción con 30,7 \%, que correspondía a 6829 t, seguida de la región Central y Noreste con 28,4 \% (6315 t) y 21,4\% (4765 t), respectivamente (Figura 3). En el 2019 la región Centro fue la que obtuvo mayor participación con el 37,9 \% (24 252 t), con los estados de México, Hidalgo y Puebla como los mayores productores con 14,5, 10,6 y $6,9 \%$, equivalente a 9289; 6770 y 4401 t, respectivamente. La segunda región en aportación fue la Centro occidente con 27,7 \% (17 741 t), en esta región los estados que aportan más fueron Zacatecas con 6,7 \% (4 279 t) y Jalisco con 7,1 \% (4536t); la región Sur sureste aportó el 22,4 \%, con una producción de 14343 t; los estados de mayor aportación fueron Veracruz 8,5 \% (5425 t) y Oaxaca con 3,8 \% (2426 t).

La región Noroeste fue la que tuvo la mayor TCMA en el periodo de 1980 a 2019 con 3,6 \%, seguida por las regiones Centro, Sureste, Centro occidente y Noreste, con 3,4; 3,4; 2,4 y $0,3 \%$, respectivamente. La TCMA nacional fue de $2,7 \%$.

\section{Precios de ovinos}

Se tomó el precio promedio del dólar del mes de febrero de 2021 que correspondió a 20,3144 \$ USD ${ }^{-1}$. En la Figura 4, se muestran los precios pagados a los productores en pie de 1980 a 2019, el ovino fue la especie mejor pagada en 2019 a 1,81 USD kg-1 ${ }^{-1}$, seguida de los bovinos (Bos taurus), cabras (Capra hircus), porcinos (Sus scrofa) y pollo (Gallus gallus domesticus) con 1,78; 1,60;1,39; $1,13 \mathrm{USD} \mathrm{kg}^{-1}$, respectivamente.

El ovino en pie fue mejor pagado a pesos constantes de 1984 a 2019 en comparación a otras especies pecuarias (Figura 5). En 2019 los precios pagados fueron 1,74; 1,69; 1,54; 1,34 y 1,08 USD kg${ }^{-1}$ de ovinos, bovinos, caprinos, porcinos y pollos, respectivamente. 


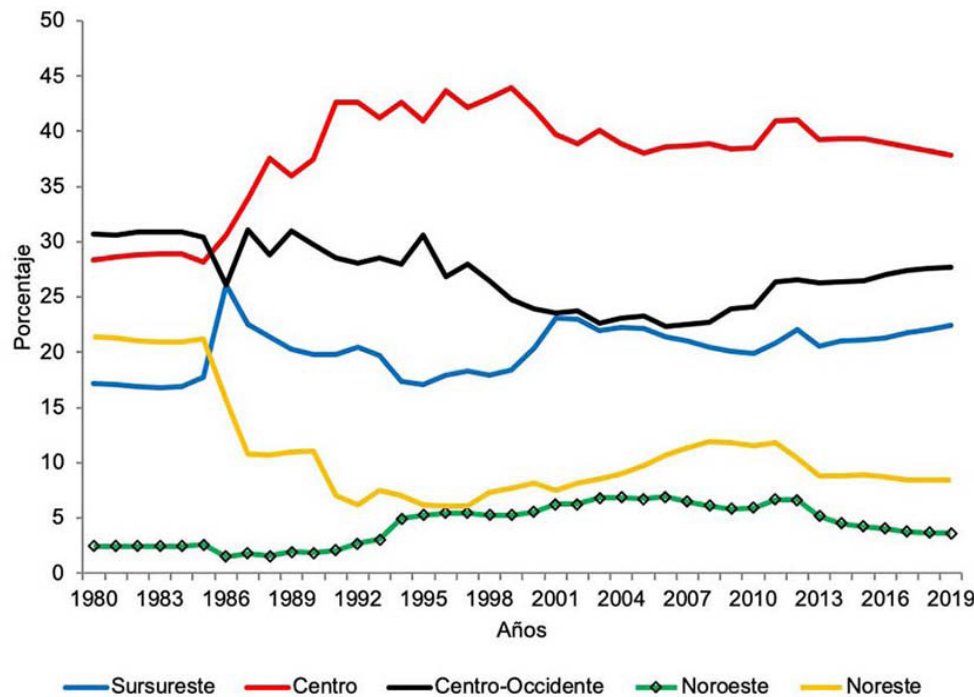

Figura 3. Participación por región socioeconómica de México de producción de carne de ovino (Ovis aries) desde 1980 hasta 2019. Fuente: elaborado con datos de SIAP (2021).

Figure 3. Participation per socioeconomic region in Mexico of sheep (Ovis aries) meat production from 1980 to 2019 . Source: Developed with SIAP (2021) data.

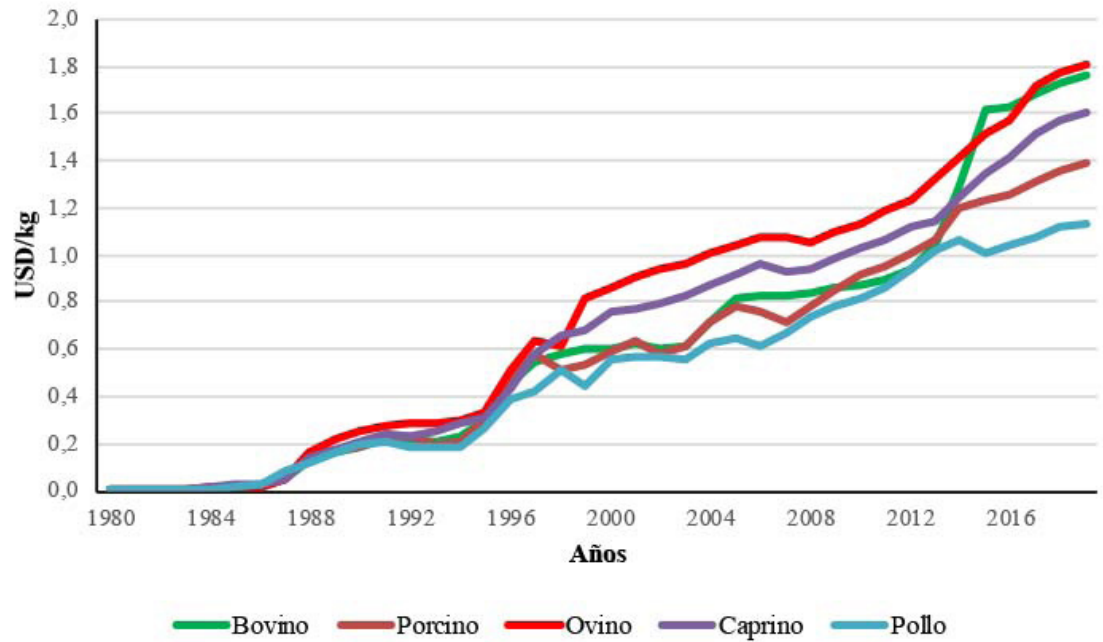

Figura 4. Precios pagados al productor de diversas especies pecuarias en pie (animal vivo para engorda o ser sacrificado), México, 1980-2019. USD kg-1. Fuente: elaborado con datos de SIAP (2021).

Figure 4. Prices paid to the producer of different live livestock species (live animal to be feedlot or slaughtered), Mexico, 1980 to 2017. USD kg ${ }^{-1}$. Source: Developed with SIAP (2021) data.

Los precios pagados constantes en dólares estadunidenses, el ovino fue el que mostró el mejor precio con respecto a las otras especies (bovinos, caprinos, porcinos y aves) (Cuadro 3). Se tomó el precio promedio del dólar 


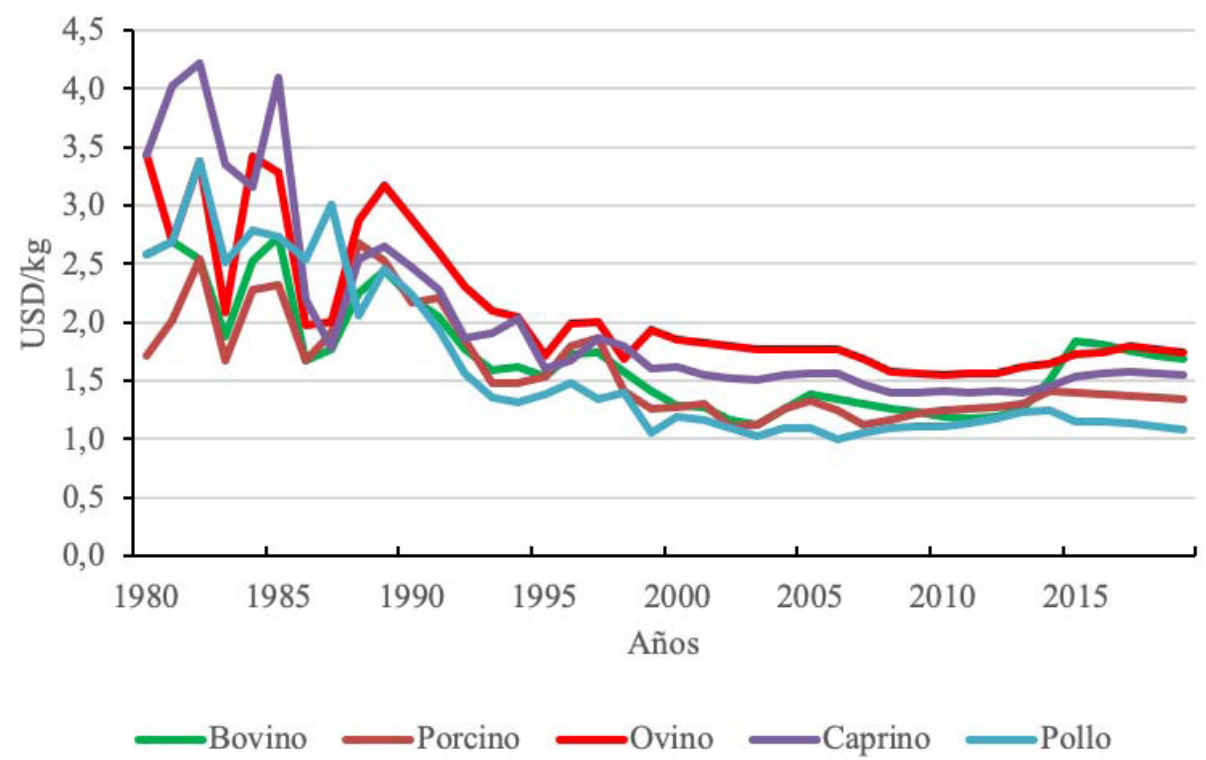

Figura 5. Precios pagados a productores (USD kg ${ }^{-1}$ ) de diversas especies pecuarias en pie (animal vivo para engorda o ser sacrificado), México, 1980-2019. Fuente: Elaborado con datos de SIAP (2021).

Figure 5. Prices paid to producers (USD kg-1) of different live livestock species (live animal to be feedlot or slaughtered). Mexico, 1980-2019. Source: Developed with SIAP (2021) data.

Cuadro 3. Precios pagados de diferentes especies pecuarias en pie (animal vivo para engorda o ser sacrificado) en México, en dólares estadunidense. 1980 y 2019.

Table 3. Prices paid of different live livestock species (live animal to be feedlot or slaughtered) in Mexico in United States Dollars. 1980 and 2019.

\begin{tabular}{cccc}
\hline Especie & $\mathbf{1 9 8 0}$ & $\mathbf{2 0 1 9}$ & Diferencia \\
\hline Ovinos (Ovis aries) & 3,44 & 1,74 & 1,70 \\
Bovinos (Bos taurus) & 2,58 & 1,69 & 0,89 \\
Caprinos (Capra hircus) & 3,44 & 1,54 & 1,89 \\
Porcinos (Sus scrofa) & 1,72 & 1,34 & 0,38 \\
Pollo (Gallus gallus domesticus) & 2,58 & 1,08 & 1,49 \\
\hline
\end{tabular}

Fuente: elaborado con datos de SIAP (2021). Source: Developed with SIAP (2021) data.

del mes de febrero de 2021 que correspondió a 20,3144 pesos por \$ USD. Para el caso de los ovinos se dejó de percibir 1,70 \$ USD kg-1 en el periodo de estudio (1980 a 2019).

\section{Estacionalidad de la producción y de precios de ovinos}

La tendencia de la producción se aprecia en la Figura 6, así como los incrementos y decrementos que se tienen; por su parte, el precio presenta una mayor variabilidad; las fluctuaciones más pronunciadas en incremento del precio se dieron en los meses de octubre de 2012 a enero de 2013 con $14,4 \%$ equivalente a $0,20 \mathrm{USD} \mathrm{kg}^{-1}$, en junio de 2005 con un $14,3 \%$ con 0,17 USD kg $^{-1}$, en mayo y junio de 2016 con un incremento de $12,4 \%$ con 0,23 
USD kg ${ }^{-1}$ de ovino en pie, las disminuciones más representativas se dieron de septiembre a noviembre de 2010, fue del 10,3\%, en julio del 2010 con 10,2 \%, de enero a abril 2008 de $8,7 \%$ y agosto de 2006, con $8,5 \%$ equivalente en Dólares estadunidenses por kilogramo de 0,$12 ; 0,13 ; 0,10$ y 0,12 , respectivamente.

Según, las líneas de tendencia, se puede apreciar que al final del periodo de análisis hay propensión a unirse, lo que indica que los precios han crecido más que la producción (Figura 6).

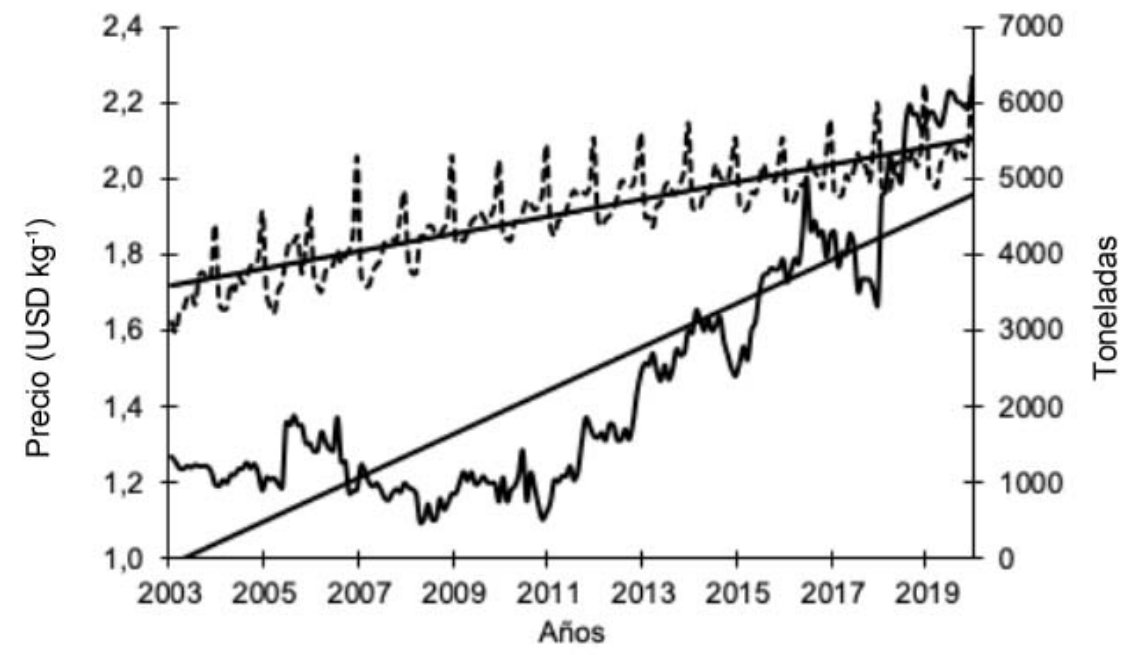

Figura 6. Producción y precios de ovinos (Ovis aries) en pie (animal vivo para engorda o ser sacrificado) en México, enero del 2003 a diciembre de 2019. Fuente: elaborado con datos de SIAP (2021); Sistema Nacional de Información e Integración de Mercados [SNIIM] (2021).

Figure 6. Production and process of standing sheep (live animal to be feedlot or slaughtered) sheep (Ovis aries) in Mexico, from January 2003 to December 2019. Source: Developed with SIAP (2021) and SNIIM (2021) data.

El índice de estacionalidad para la producción de ovinos en pie mostró que los meses de enero a mayo fueron en los que se tuvo menor producción y de junio a diciembre se dio la mayor producción, el índice va de 90,8 hasta $119,0 \%$ (Figura 7).

La variabilidad de la estacionalidad de los precios en pie de ovinos fue desde 99,1 hasta 101,5\%, la variación fue de 2,4\%; el mes de junio fue donde se tuvo el mejor precio con respecto a los precios pagados en canal, la fluctuación fue de 1,6 \%. En agosto se pagó mejor la carne en canal de ovinos, la variación fue de 99,1 a 100,7 \% (Figura 8).

El comportamiento del índice estacional de producción precio de ovino en pie y carne en canal, se muestra en la Figura 8, donde el índice de producción de junio a diciembre se encontró por arriba del 100, su punto máximo se obtuvo en diciembre y el punto mínimo fue en febrero; por su parte, el precio de ovinos mínimo fue en abril y el punto mayor fue en junio. La carne en canal mostró su punto mínimo en enero y el máximo en junio. La producción en el transcurso del año tuvo mayor variabilidad en su índice con respecto al precio de ovinos en pie y carne en canal que se mantuvo constante todo el año, donde existió menos producción debió de tener mejor precio y en comparación con el mes de diciembre, donde existió la mayor producción se tuvo un precio bajo para la carne en canal (Figura 9).

La variabilidad de las importaciones tanto de ovinos en pie como en carne se muestran en la Figura 10. Los ovinos en pie presentaron una variación de $77,9 \%$ en septiembre hasta $124,2 \%$ en junio, el punto máximo de la 


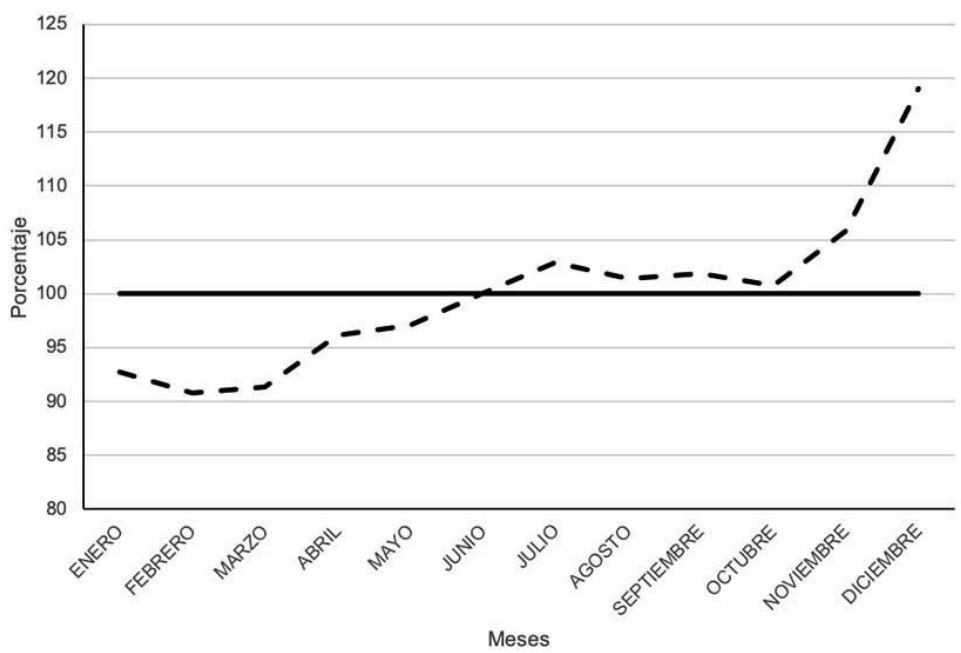

Figura 7. Índice de estacionalidad de producción de ovino (Ovis aries) en pie (animal vivo para engorda o ser sacrificado), México, enero de 2003 a diciembre 2019. Fuente: elaborado con datos de SIAP (2021).

Figure 7. Seasonal index of live sheep (Ovis aries) production (live animal to be feedlot or slaughtered), Mexico, from January 2003 to 2019. Source: Developed with SIAP (2021) data.

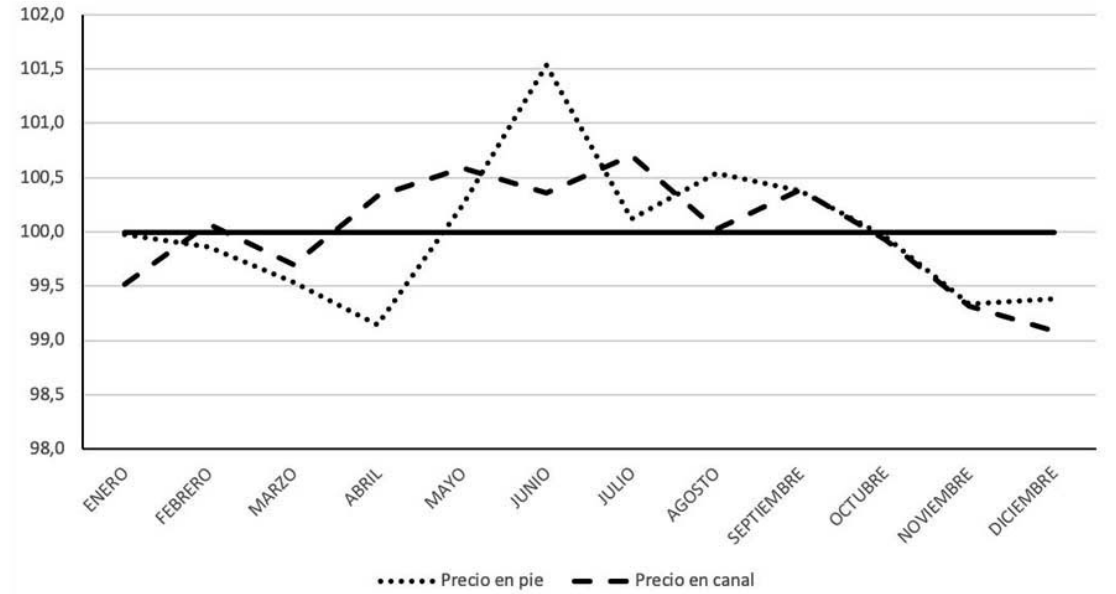

Figura 8. Índice de estacionalidad de precios en pie y carne de canal de ovinos (Ovis aries) en México, enero de 2003 a diciembre 2019. Fuente: elaborado con datos de SIAP (2021) y SNIIM (2021).

Figure 8. Seasonal index of live sheep (live animal to be feedlot or slaughtered) and sheep carcass (Ovis aries) prices in Mexico from January 2003 to December 2019. Source: Developed with SIAP (2021) and SNIIM (2021) data.

carne en canal fue 132,6 \% en el mes de junio y el mínimo en octubre con 77,9\%. En el primer semestre del año, las importaciones de carne en cinco meses estuvieron por arriba del 100, excepto el mes de febrero; el segundo semestre, las importaciones estaban por abajo del promedio; los ovinos en pie en el primer semestre, los meses de febrero y marzo, estaban por abajo del 100, en el segundo semestre tres meses estuvieron por abajo del promedio y el resto por arriba del 100. El mes de junio fue el punto máximo de importaciones, tanto en ovinos en pie como en carne, también coincidió donde se obtuvo el mejor precio en pie y la carne estuvo por arriba de los 100 puntos. 


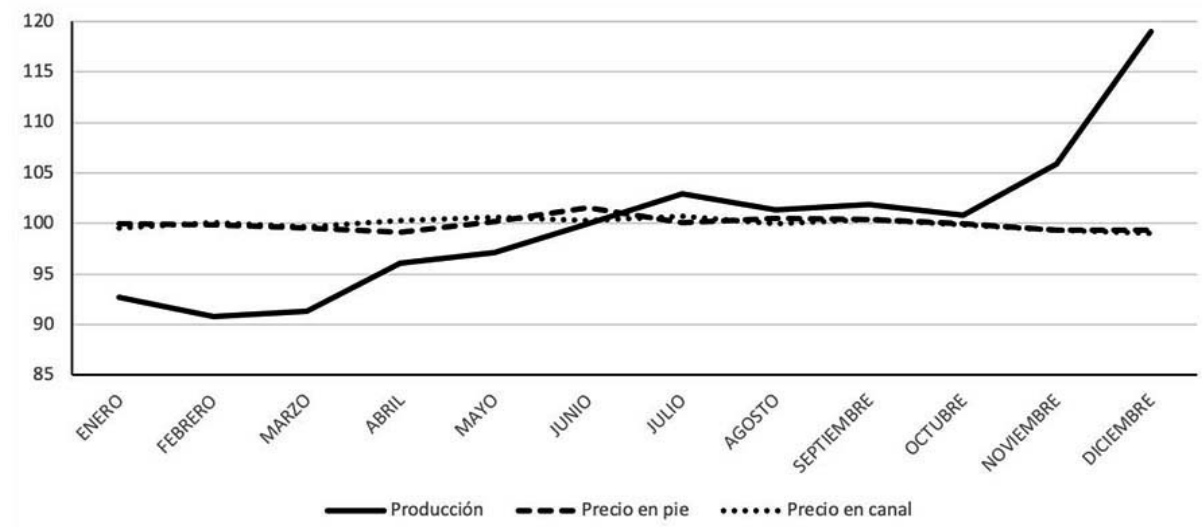

Figura 9. Producción, precio en pie y carne en canal de ovinos (Ovis aries) en México, enero de 2003 a diciembre 2019. Fuente: elaborado con datos de SIAP (2021) y SNIIM (2021).

Figure 9. Production, live sheep (Ovis aries) and sheep carcass prices in Mexico from January 2003 to December 2019. Source: Developed with SIAP (2021) and SNIIM (2021) data.

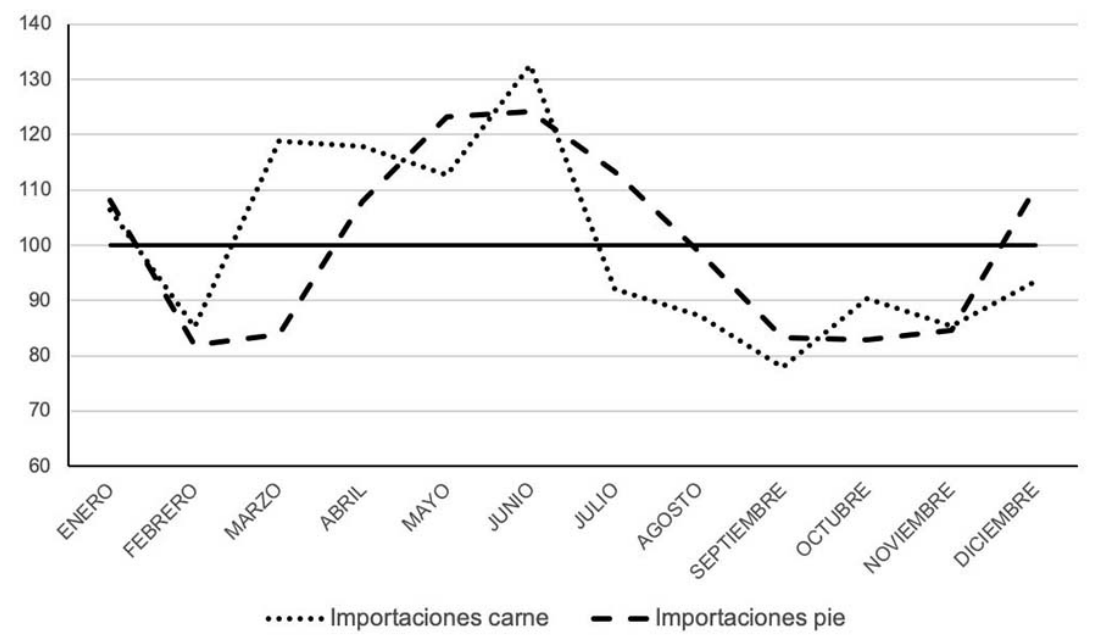

Figura 10. Índice de estacionalidad para importaciones de ovinos (Ovis aries) en México, enero de 2003 a diciembre 2019. Fuente: elaborado con datos de SNIIM (2021).

Figure 10. Seasonal index for sheep (Ovis aries) imports in Mexico from January 2003 to December 2019. Source: Developed with SNIIM (2021) data.

El índice estacional de producción de enero a junio estuvo por abajo del 100 y de julio a diciembre por arriba de los 100 puntos, su punto máximo se obtuvo en diciembre; por su parte, el índice de estacionalidad de importaciones en pie y en carne, su punto mínimo fue en septiembre y el máximo en junio (Figura 11).

\section{Importaciones de ovinos y carne}

Las importaciones de ovinos en pie en 1970 fueron de 80228 y para 2019 de 7752, con un máximo en 1992, con 958 mil ovinos, mientras que en 2012 fue cuando se registró el menor número de ovinos importados (308) (Figura 12). Las importaciones de carne de ovino pasaron de 161 t en 1970 a 6782 t en 2019; el incremento fue 


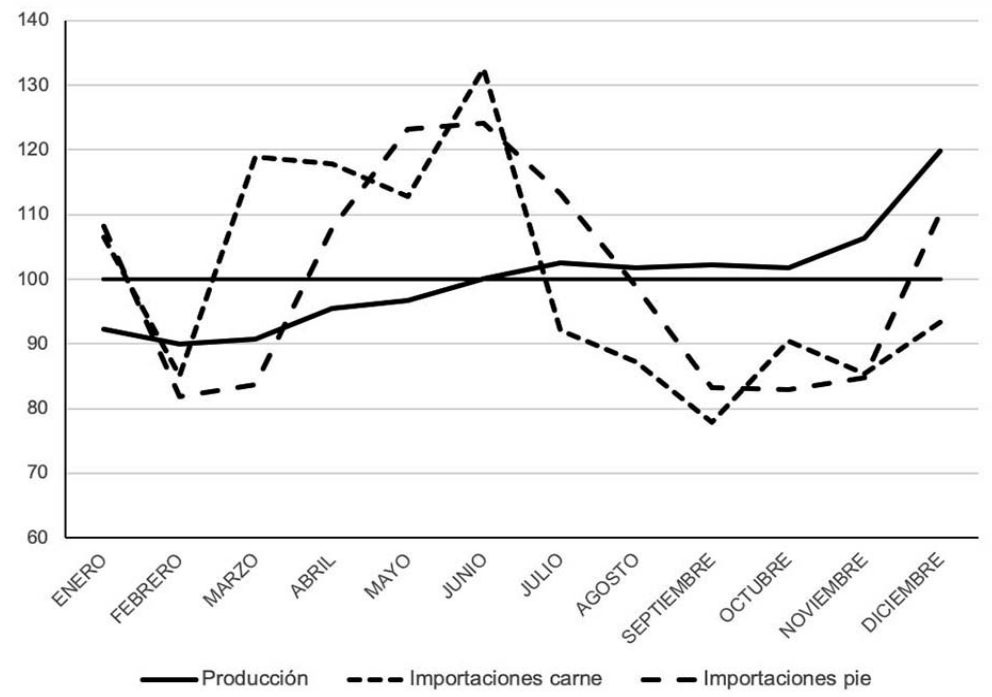

Figura 11. Índice de estacionalización de producción e importaciones de ovinos (Ovis aries) en México, enero de 2003 a diciembre 2019. Fuente: elaborado con datos de SIAP (2021) y del SIAVI (2021).

Figure 11. Seasonality index of sheep (Ovis aries) imports and production in Mexico, from January 2003 to December 2019. Source: Developed with SIAP (2021) and SIAVI (2021) data.

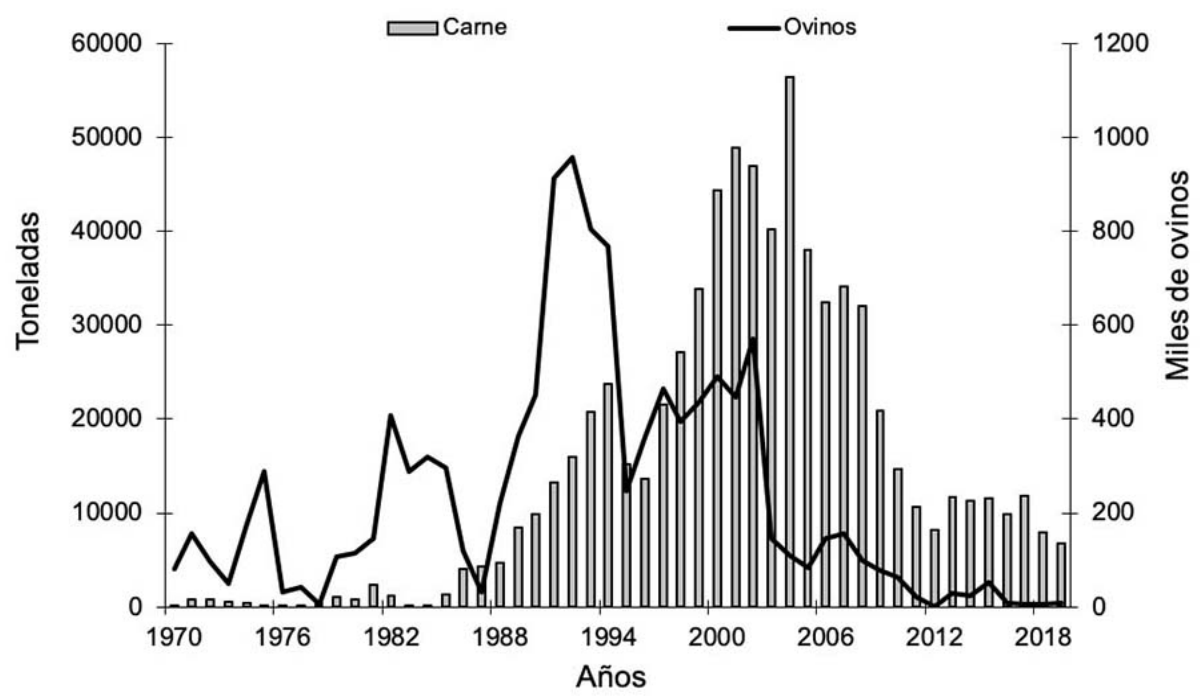

Figura 12. Importaciones de ovinos (Ovis aries) en pie y carne, desde 1970-2019, México. Fuente: elaborado con datos de Organización de las Naciones Unidas para la Alimentación y la Agricultura [FAOSTAT] (2018) y del SIAVI (2021).

Figure 12. Imports of live sheep (Ovis aries) imports live and meat, since 1970 to 2019, Mexico. Source: Developed with FAOSTAT (2018) and SIAVI (2021) data.

$6621 \mathrm{t}$ con una tasa de crecimiento media anual de 7,8 \%; en 1985 fue cuando se inició un crecimiento constante de importaciones hasta 2004, año en que se importó la cantidad 56367 t (Figura 12). De 1970 a 1992 las importaciones eran principalmente de ovinos en pie, después estas fueron sustituidas por carne. 
Las importaciones de ovinos en pie fueron principalmente de Estados Unidos de América, con participación de Australia y Nueva Zelandia en menor proporción y en algunos años (Figura 13). Con base en información de la Secretaría de Economía de 2003 a 2019, existieron tres fracciones arancelarias para la importación de ovinos en pie con pedigree o certificado de alto registro, para abasto y los demás animales vivos de la especie ovina. El número de ovinos para abasto es la fracción que más animales importó en comparación con las otras dos fracciones, con el 2003 como año que importó el mayor número de ovinos (143 mil cabezas) y la fracción de alto se registró en 2007, cuando se importaron 35 mil semovientes para pie de cría.

Las importaciones de carne de ovino fueron de 1986 a 1990, principalmente de Estados Unidos de América y de 1991 a 2019 fueron de Australia, Nueva Zelandia y, en menor proporción, Estados Unidos de América (Figura 14).

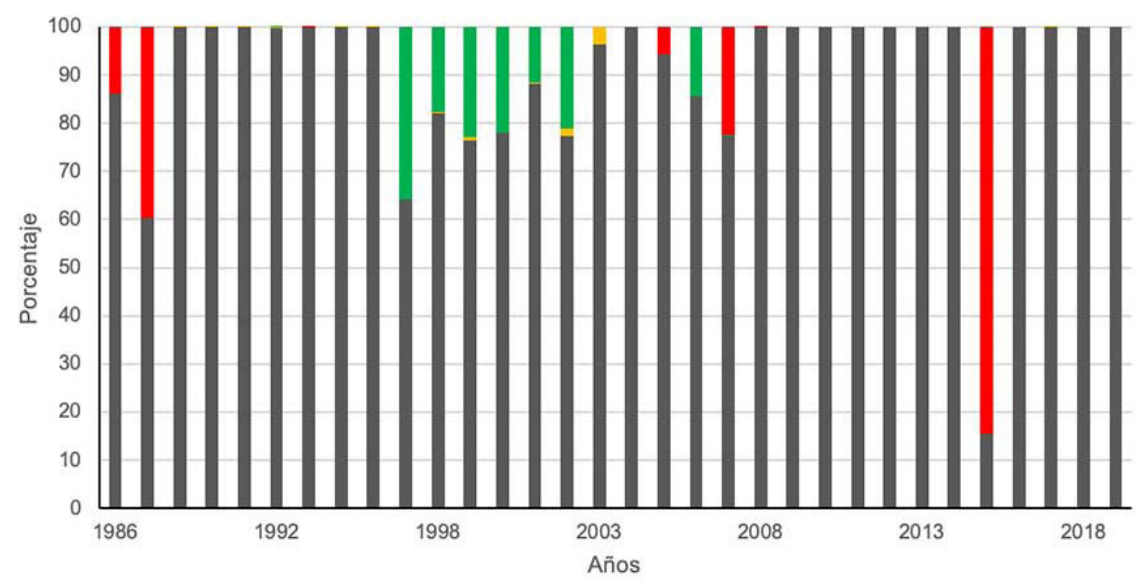

Figura 13. Participación de importaciones por país de ovinos (Ovis aries) en pie. México, 1986-2019.

Figure 13. Participation per country of live sheep (Ovis aries) imports. Mexico, 1986-2019.

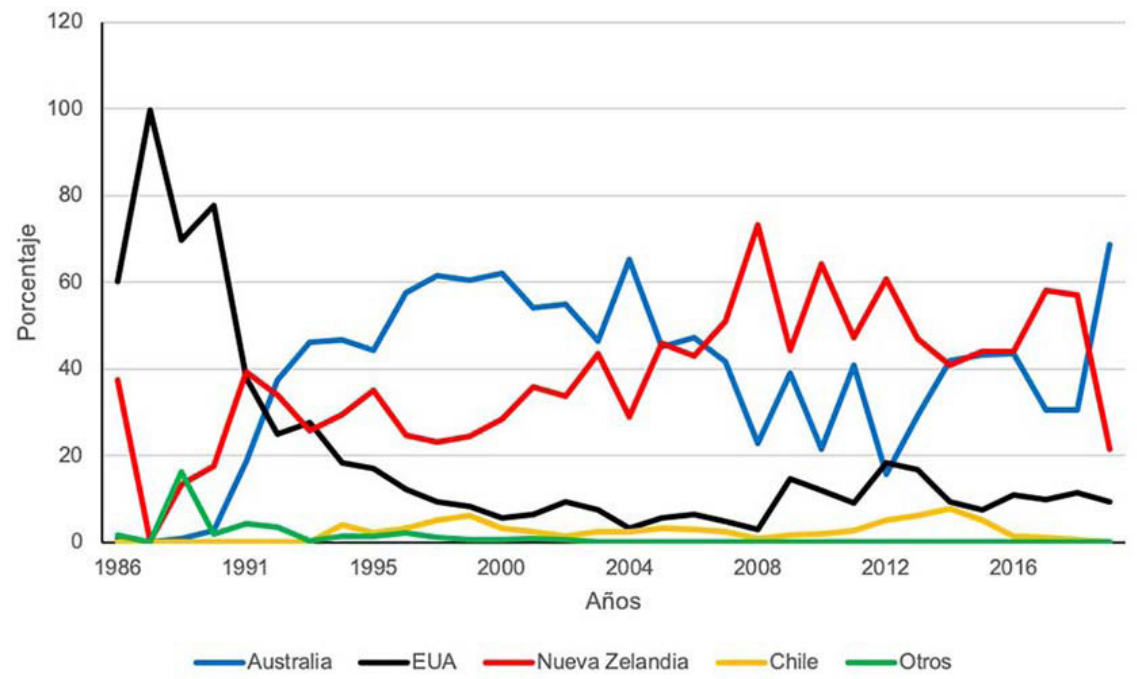

Figura 14. Participación de importación de carne de ovino (Ovis aries) por país. México, 1986-2019. Fuente: elaborado con datos de FAOSTAT (2018) y del SIAVI (2021).

Figure 14. Participation per country of sheep meat (Ovis aries) imports, Mexico 1986-2019. Source: Developed with FAOSTAT (2018) and SIAVI (2021) data. 


\section{Consumo de carne de ovino}

El consumo nacional aparente (CNA) en México en 1970 fue 22545 t y en el 2019 fue 70812 t, con una tasa de crecimiento media anual de 2,3\% en el periodo de estudio; en 2004 se tuvo el mayor consumo (102 690 t) de las importaciones de carne de ovino (Figura 15). El consumo per cápita de carne de ovino en México en 2019 fue de $567 \mathrm{~g}$ de 1970 a 2019 y el consumo por persona tuvo una tasa de crecimiento media anual del 0,39\% durante cincuenta años. En 1970 el consumo fue de $467 \mathrm{~g}$, el incremento fue de $100 \mathrm{~g}$, el año de 2004 tuvo mayor consumo de este con alrededor de $1 \mathrm{~kg}$ por persona (Figura 15).

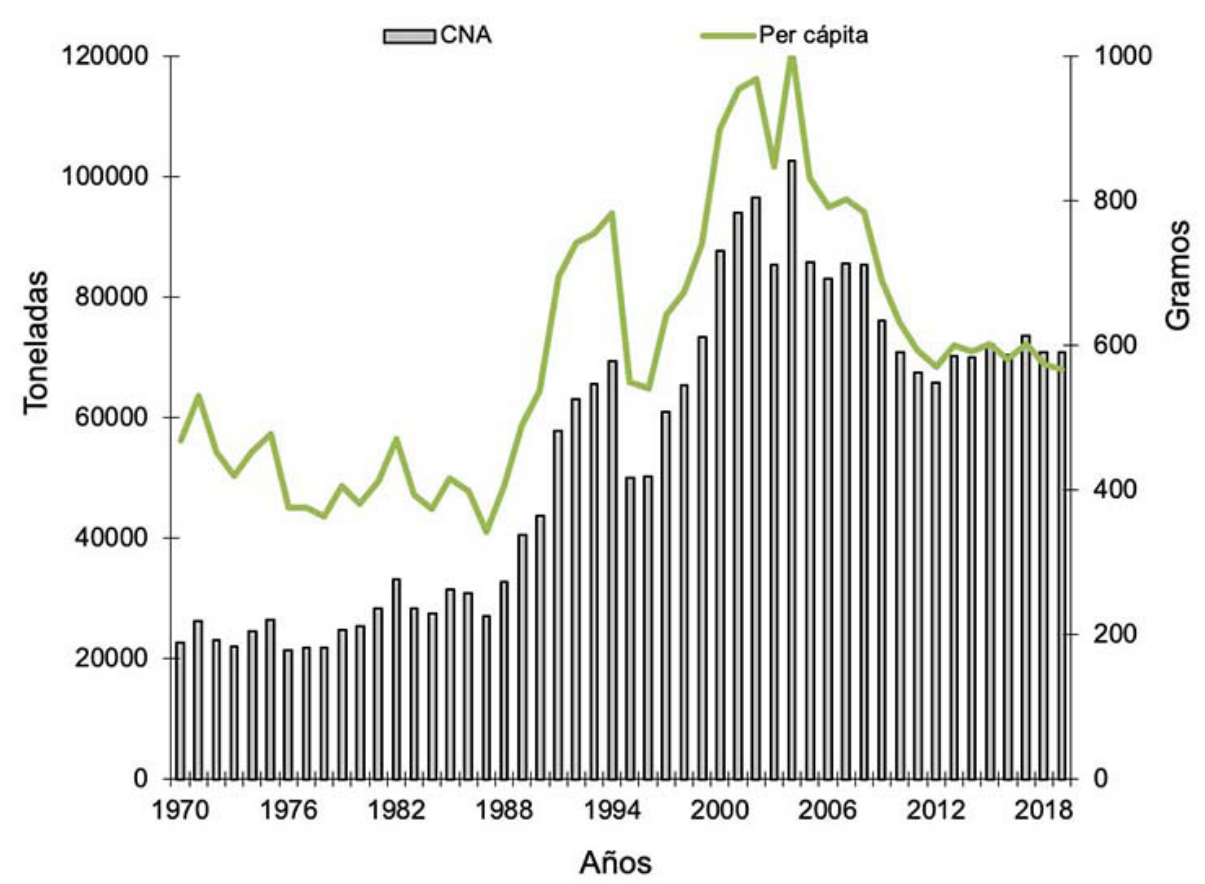

Figura 15. Consumo nacional aparente y per cápita de carne de ovino (Ovis aries) en México. 1970-20219. Fuente: elaborado con datos del Instituto Nacional de Estadística, Geografía e Informática [INEGI] (2021) y del SIAP (2021).

Figure 15. Apparent national and per capita national sheep (Ovis aries) meat consumption in Mexico. 1970-2019. Source: Developed with INEGI (2018) and SIAP (2021) data.

Las importaciones representaron el 7,8 \% (1765 t) en 1970 y en 2019 fueron de 9,6\% (6 782 t) del consumo. En el periodo de estudio (1970 a 2019) existieron variaciones en la participación de las importaciones en el consumo, en el 2000 la participación fue de 61,8 \% (54 206 t), seguido de los años de 2001, 2002 y 2004, con 61,5 $\%$ (57 753 t); 61,4\% (58 335 t) y 56,9\% (58 375 t), respectivamente (Figura 16). 


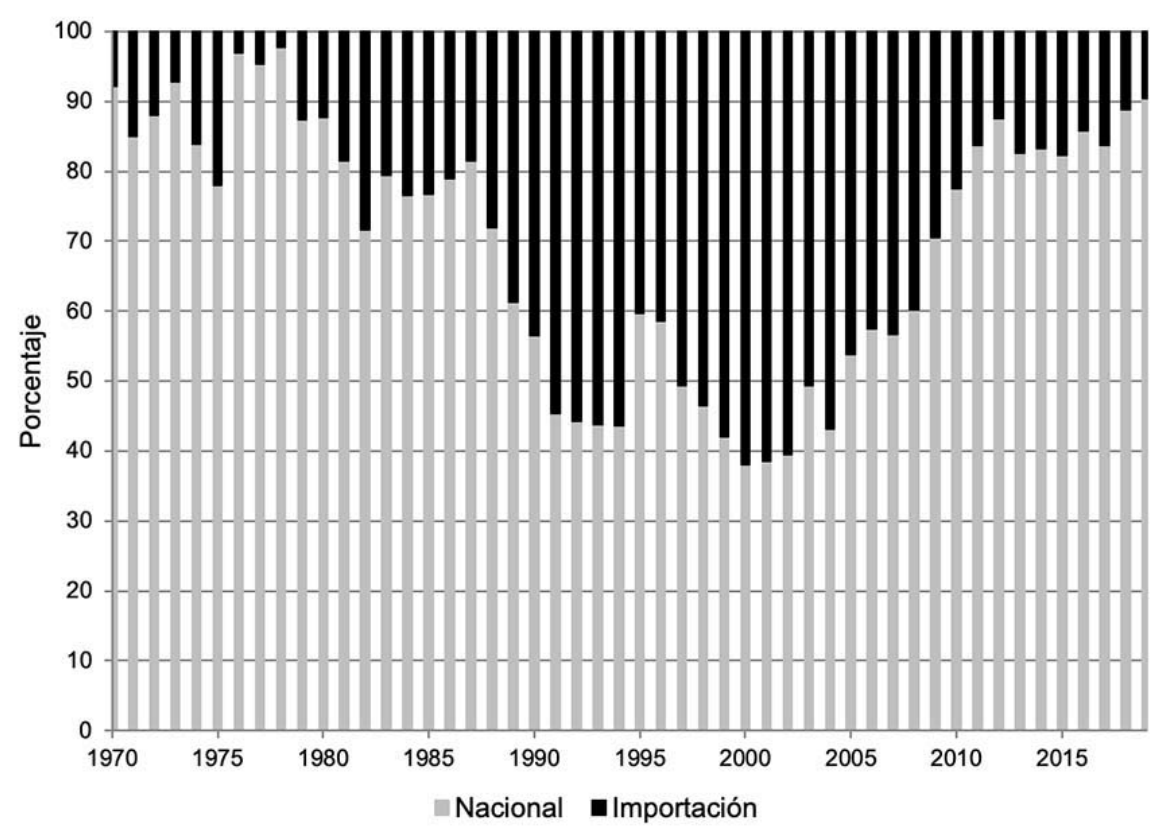

Figura 16. Participación de las importaciones de carne de ovinos (Ovis aries) en México, 1970-2019. Fuente: elaborado con datos de FAOSTAT (2018), SIAP (2021) y del SIAVI (2021).

Figure 16. Share of sheep (Ovis aries) meat imports' participation in Mexico, 1970 - 2019. Source: Developed with FAOSTAT (2018), SIAP (2021) y SIAVI (2021) data.

\section{Discusión}

La orientación de la ovinocultura mexicana es hacia la producción de carne, se obtienen altos precios en pie y canal en comparación con otras especies pecuarias (Carrera-Chávez, 2008). El ovino en pie fue mejor pagado con respecto a otras especies pecuarias a pesos contantes; la carne en canal también fue mejor pagada con respecto a los caprinos, porcinos, bovinos y pollos: en 2012 los precios fueron de 1,56; 1,41; 1,$27 ; 1,19$ y $1,18 \mathrm{USD} \mathrm{kg}^{-1}$, respectivamente En 1980 el precio pagado al productor de ovino fue de $3,44 \mathrm{USD} \mathrm{kg}^{-1}$ y en 2016 de $1,74 \mathrm{USD} \mathrm{kg}^{-}$ 1; esto es que el productor por hacer la misma actividad después de 37 años ha dejado de percibir $1,70 \mathrm{USD} \mathrm{kg}^{-1}$ de ovino en pie (Bobadilla-Soto et al., 2015). Estos datos concuerdan que los encontrados en este estudio donde el ovino en pie junto con en carne en canal es mejor pagada en 2019.

El incremento de la producción de octubre a diciembre fue del 18,1\%, el aumento más pronunciado del año. Donde existió menor producción fue en los meses de febrero y marzo, lo que concuerda con la Semana Santa, donde la demanda de carnes rojas disminuye por el incremento en el consumo de pescado y carnes blancas. Durante el segundo semestre del año, la producción de carne de cerdo se ubicó por arriba del promedio (De-los-Santos-Ramos et al., 2017), mismo fenómeno se presentó con la producción de ovinos, donde el segundo semestre del año se presentó mayor producción. La estacionalidad de la producción de ovinos estuvo determinada por varios factores como la temperatura, latitud, altitud y el foto periodo, este último, fue el más repetible y con variabilidad nula entre años. Las borregas de lana fueron más estacionales con respecto a las de pelo, lo cual es un mecanismo de adaptación como estrategia para minimizar el impacto negativo del ambiente (temperatura, humedad y disponibilidad de alimento), en la supervivencia de las crías de manera que los nacimientos ocurrieron en la época más favorable del año, con abundancia de pastos y temperatura ambiental confortable (Arroyo, 2011). La mayor producción se dio en el 
segundo semestre del año, donde la época de lluvias se encuentra presente y la producción de alimento se incrementa. Los sistemas de producción de ovinos se han desarrollado de manera extensiva a base de pastoreo sobre áreas con vegetación nativa y comunales (Vázquez-Martínez et al., 2009).

Cuando el índice de estacionalidad varió entre 95 y $105 \%$ fue muy bajo, esto significa que el precio se mantuvo estable todo el año. El ovino en pie fue mejor pagado en junio, la carne en canal de la misma especie fue mejor pagada en agosto, el menor precio se presentó en diciembre y el ovino en pie mostró el precio más bajo en enero. En un studio realizado en cerdos, el índice estacional de los precios de cerdo en pie indicó que en los meses de abril y mayo fue cuando menor precio se tuvo, y los meses que mejor se pagó la carne de esta especie fueron julio y agosto (De-los-Santos-Ramos et al., 2017). Cuando el índice de estacionalidad estuvo entre 80 y 120, fue moderado.

El índice de estacionalidad de los precios, tanto de ovinos en pie como de carne en canal, existió poca variabilidad, que fue de 2,6 y $1,8 \%$, respectivamente, lo que indica que los precios fueron estables todo el año; por su parte, la producción en el primer semestre estuvo por debajo de los 100 puntos, por lo cual los precios deberían de estar por arriba de los 100 puntos, pero no ocurrió por las importaciones, ya que el primer semestre en promedio estuvo arriba de la media, lo cual estabilizó los precios de mercado; en el segundo semestre, las importaciones en promedio se encontraban debajo de los 100 puntos y la producción estuvo por arriba de este punto, lo que estabilizó los precios del segundo semestre del año.

Para la producción y las importaciones, los meses donde se tuvieron los puntos más bajos fueron en febrero y marzo, meses que con concuerdan con la cuaresma y la Semana Santa, donde el consumo de carnes rojas disminuyó, el consumo de la carne de ovinos se realizó de barbacoa los fines de semana y los meses de mayor consumo fueron en julio y agosto, que coincidió con las salidas de las escuelas y en diciembre por la fiesta de fin de año. La estacionalidad fue motivada por efectos de mercado, la demanda estuvo vinculada a la parte cultural y religiosa, con los diferentes niveles de poder adquisitivo, y los hábitos de consumos (De-los-Santos-Ramos et al., 2017).

De acuerdo con un estudio realizado con el índice estacional en el comportamiento de carne de cerdo en precio y producción, el precio más bajo fue en el mes de mayo y el máximo en julio, la producción al inicio del año fue baja y conforme transcurrieron los meses del año se incrementó la producción, con diciembre como el mes de mayor producción (Martínez-Castañeda et al., 2011; 2013); estos datos coincidieron con los obtenidos en este trabajo, donde la producción estuvo por debajo de los 100 puntos y el segundo semestre por arriba de estos puntos.

La importancia del índice estacional es que muestra las fluctuaciones de los precios durante el año; entre más años se cuente con información, el índice será más preciso (Barrera-Islas \& Chalita-Tovar, 2015). Los resultados obtenidos contribuyen a mejorar el conocimiento del funcionamiento de los mercados y a conocer el comportamiento de los precios, lo cual permite tomar mejores decisiones a la hora de producir, es decir, buscar desfasar la producción en aquellos meses que se tienen precios altos (Lobos-Andrade \& Muñoz-Ibáñez, 2005).

Para este trabajo, también se contemplaron la fracción arancelaria de ovinos con pedigree o certificado de alto registro que se importaron para los programas de repoblamiento, pero este ganado, de donde son traídos, tuvieron condiciones ambientales y de manejo muy diferentes a las condiciones de México, lo cual en lugar de ser una solución para los productores se convierte en problema, por lo que los animales al final son vendidos para la elaboración de la barbacoa como lo muestra el trabajo realizado en el Estado de México en 2007. Diecisiete meses después de haberse entregado los subsidios para la compra de ovinos para pie de cría al momento de la encuesta, $16 \%$ de las unidades de producción familiares ya no contaban con una sola cabeza de ganado, $36 \%$ decrecían y solo $48 \%$ de los productores apoyados estaban estables o creciendo. En este último grupo, el ritmo de crecimiento estimado fue de 0,6 vientres por año, mientras los que estaban decreciendo lo hacían a un ritmo de menos diez vientres por año, por lo que en forma global la tasa de crecimiento de los rebaños era de menos cuatro vientres por año. Dado que, en general, el monto de los subsidios permitió adquirir un rebaño de quince vientres en promedio, significó que a este ritmo de pérdida del activo ganadero en solo cuatro años, se perdió la inversión pública (subsidio) y la inversión privada (aportación del productor con recursos propios) (Martínez-González et 
al., 2011). Las políticas al sector agropecuarias no han sido las adecuadas, por ello más del $50 \%$ de las unidades estuvieron cerradas o decreciendo. Autores como González-Estrada \& Orrantia-Bustos (2006), denunciaron las ineficiencias en la asignación de recursos al sector agropecuario y plantearon la necesidad de cambios estructurales en la política nacional.

El mayor consumo per cápita coincidió cuando mayor carne se importó, esto nos indicó que el consumo estuvo más ligado a las importaciones que a la producción nacional (Bobadilla-Soto et al., 2017).

\section{Conclusiones}

La producción de carne de ovinos tuvo una tasa de crecimiento media anual de 2,28 \%, en el periodo de 1970 a 2019 finalizó con 64030 t. La región Centro de México fue donde se concentró la producción en 2019 y aportó $37,9 \%$ con 24252 t.

La carne de ovino en el periodo de estudio fue la mejor pagada a pesos constantes con respecto a otras carnes en 2019 , los precios pagados fueron 35,$30 ; 34,33 ; 31,34 ; 27,15$ y $22,02 \$ \mathrm{~kg}^{-1}$ de ovinos, bovinos, caprinos, porcinos y pollos, respectivamente. Con el índice estacional se encontró una marcada estacionalidad en la producción en los meses de enero a mayo donde la producción fue inferior al $100 \%$ y el resto del año la producción se incrementó (>100 \%); sin embargo, el precio se mantuvo constante durante todo el año, esto se debió a las importaciones, ya que estas estabilizaron el precio en la época de poca producción en México.

Existió una fuerte dependencia por las importaciones de carne de ovino para satisfacer el mercado nacional en los últimos años, con importaciones que pasaron de 7,8\% a 61,8\%; el consumo per cápita se incrementó en cincuenta años en $100 \mathrm{~g}$ y finalizó en el 2019 con 567 g por persona, donde el incrementó fue de $18 \%$.

\section{Referencias}

Arroyo, Y. (2011). Estacionalidad reproductiva de la oveja en México. Tropical and Subtropical Agroecosystems, 14(3), 829845. http://www.scielo.org.mx/pdf/tsa/v14n3/v14n3a1.pdf

Améndola, R., Castillo, E., \& Martínez, P. (2005). Country pasture and forage resource profiles: México. Food and Agricultural Organization. http://www.fao.org/ag/AGP/agpc/doc/Counprof/Mexico/Mexico.htm

Barrera-Islas, D., \& Chalita-Tovar, L. (2015). Metodología para el análisis de mercados agropecuarios. Editorial BBA.

Bobadilla-Soto, E. E., Flores-Padilla, J. P., \& Perea-Peña, M. (2017). Comercio exterior del sector ovino mexicano antes y después del Tratado de Libre Comercio con América del Norte. Economía y Sociedad, 37, 35-49. https://www. redalyc.org/jatsRepo/510/51054506003/html/index.html

Bobadilla-Soto, E., Salas-Razo, G., Padillas-Flores, J., \& Perea-Peña, M. (2015). Unit displacement of sheep production in Mexico by effect of imports. International Journal of Development Research, 5(2), 3607-3612. https://www. researchgate.net/publication/324173926_UNIT_DISPLACEMENT_OF_SHEEP_PRODUCTION_IN_MEXICO_ BY_EFFECT_OF_IMPORTS

Carrera-Chávez, B. (2008). La ovinocultura en México: alternativa para los productores rurales. Avances Cuadernos de Trabajo, 207, 1-17. https://studylib.es/doc/7682092/la-ovinocultura-en-m\%C3\%A9xico--\%C2\%BFalternativa-paralos-productores 
De-los-Santos-Ramos, M., Perea-Peña, M., Flores-Padilla, J. P., \& Bobadilla-Soto, E. E. (2017). Estacionalidad de la producción y precios de cerdo en México. Realidad Económica, 3(1), 27-38. https://www.realidadeconomica.umich.mx/index_ files/estacionalidad_de_la_produccion_y_precios_del_cerdo_2.pdf

Díaz-Sánchez, C. C., Jaramillo-Villanueva, J. L., Bustamante-González, A., Vargas-López, S., Delgado-Alvarado, A., Hernández-Mendo, O., \& Casiano-Ventura, M. A. (2018). Evaluación de la rentabilidad y competitividad de los sistemas de producción de ovinos en la región de Libres, Puebla. Revista Mexicana de Ciencias Pecuarias, 9(2), 263-277. https://doi.org/10.22319/rmcp.v9i2.4495

Espejel-García, A., Barrera-Rodríguez, A. I., Rodríguez-Moreno, A., \& Santiago-Vargas, M. L. (2015). Caracterización de los productores y dinámica de adopción de innovación en el municipio de Villa Victoria, Estado de México. Ra Ximhai, 11, 17-34. https://www.redalyc.org/pdf/461/46142593001.pdf

González-Estrada, A., \& Orrantia-Bustos, M. A. (2006). Los subsidios agrícolas en México. Agricultura Técnica de México, 32(3), 323-331. http://www.scielo.org.mx/scielo.php?script=sci_arttext\&pid=S0568-25172006000300008

Instituto Nacional de Estadística, Geografía e Informática. (2021). Censo de población en México 2020. https://www.inegi.org. $\mathrm{mx} /$ temas/estructura/

Hanke, J. E., \& Reitsch, A. G. (1997). Estadística para negocios (2a Ed.). McGraw-Hill.

Herrera-Haro, J., Álvarez-Fuentes, G., Bárcena-Gama, R., \& Núñez-Aramburu, J. M. (2019). Caracterización de los rebaños ovinos en el sur de Ciudad de México, México. Acta Universitaria, 29, 1-25. https://doi.org/10.15174/au.2019.2022

Lobos-Andrade, G., \& Muñoz-Ibáñez, T. (2005). Índices de estacionalidad de los precios medios recibidos por los productores de manzanas chilenas. Pesquisa Agropecuária Brasileira, 40(11), 1051-1057. https://doi.org/10.1590/S0100204X2005001100001

Martínez, G.A. (1982). Métodos Econométricos. Colegio de Posgraduados.

Martínez-Castañeda, F. E., Bobadilla-Soto, E. E., Espinoza-Ortega, A., \& Rouco-Yañez, A. (2011). “Cobwed” y las descripciones del fenómeno de las fluctuaciones cíclicas del sistema porcino. En B. Cavalloti, B. Ramírez, F. Martínez, C. Marcof, \& A. Cesín (Eds.), La ganadería ante el agotamiento de los paradigmas dominantes (pp. 287-294). Universidad Autónoma de Chapingo.

Martínez-Castañeda, F. E., Bobadilla-Soto, E. E., \& Rouco-Yáñez, A. (2013). Fluctuaciones cíclicas de la carne de porcino. En E. E. Bobadilla-Soto, \& F.E. Martínez-Castañeda (Eds.), Porcicultura mexicana: auge y crisis de un sector (pp. 83-100). Universidad Autónoma del Estado de México.

Martínez-González, S., Aguirre-Ortega, J., Gómez-Danés, A., Ruíz-Félix, M., Lemus-Flores, C., Macías-Coronel, H., Moreno Flores,L., Salgado-Moreno, S., \& Ramírez-Lozano, M. (2010). Tecnología para mejorar la producción ovina en México. Revista Fuente, 5, 41-51. http://dspace.uan.mx:8080/jspui/bitstream/123456789/498/1/Tecnolog\%C3\%ADas\%20 para\%20mejorar\%201a\%20producci\%C3\%B3n\%20ovina\%20en\%20Mexico.pdf

Martínez-González, E. G., Muñoz-Rodríguez, M., García-Muñiz, J. G., Santoyo-Cortés, V. H., Altamirano-Cárdenas, J. R., \& Romero-Márquez, C. (2011). El fomento de la ovinocultura familiar en México mediante subsidios en activos: lecciones aprendidas. Agronomía Mesoamericana, 22(2), 367-377. https://doi.org/10.15517/AM.V22I2.11830

Molina-Cervantes, L. (2005). Aplicación de una medida de salvaguarda, a las importaciones de cortes secundarios de carne congelada de ovino, como un impulso a la cadena productiva y de comercialización ovina en México (Tesis de Licenciatura, no publicada) Universidad Autónoma del Estado de Hidalgo. 
Mondragón-Ancelmo, J., Domínguez-Vara, I., Rebollar-Rebollar, S., Bórquez-Gastélum, L., \& Hernández-Martínez, J. (2012). Margins of sheep meat marketing in Capulhuac, State of Mexico. Tropical and Subtropical Agroecosystems, 15, 105-116. http://www.revista.ccba.uady.mx/ojs/index.php/TSA/article/view/888/635

Mondragón-Ancelmo, J., García-Hernández, P., Rojas-Sandoval, L., Domínguez Vara, I., Gómez-Tenorio, G., \& RebollarRebollar, S. (2018). Caracterización de consumidores agroindustriales de carne de pequeños rumiantes en el Estado de México. Investigación y Ciencia, 74(2018), 17-24. https://doi.org/10.33064/iycuaa2018741717

Organización de las Naciones Unidas para la Alimentación y la Agricultura. (2018). FAOSTAT: Estadísticas de importación de carne de ovino en México. http://www.fao.org/faostat/es/\#data/TM

Pérez-Hernández, P., Vilaboa-Arroniz, J., Chalate-Molina, H., Martínez-Bernandino, C., Díaz-Rivera, P., \& López-Ortiz, S. (2011). Análisis descriptivo de los sistemas de producción con ovinos en el estado de Veracruz, México. Revista Científica Universidad Zulia, 21(4), 327-334. https://www.redalyc.org/articulo.oa?id=95918727007

Rouco-Yañez, A., \& Muñoz-Luna, A. (2006). El ciclo del cerdo ¿Por qué fluctúan los precios? En L. A. Muñoz (Ed.). Producir carne de cerdo en el siglo XXI, generando un nuevo orden zootécnico (pp. 465-4773). Acalanthis.

Secretaria de Economía. (2021). Regiones socioeconómicas de México. https://www.economia.com.mx/regiones_ socioeconomicas_de_mexico.htm

Sistema de Información Agroalimentaria y Pesquera. (2021). Estadísticas de producción de ovinos. https://nube.siap.gob.mx/ cierre_pecuario/

Sistema de Información Arancelaria Vía Internet. (2021). Importaciones de ovinos varias fracciones arancelarias. http://www. economia-snci.gob.mx/

Sistema Nacional de Información e Integración de Mercados. (2021). Precios diarios de carne en canal de ovinos. http://www. economia-sniim.gob.mx/nuevo/Home.aspx?opcion=/SNIIM-Pecuarios-Nacionales/MenPec. asp?var=Ovi

Troncoso, C., \& Lobos, G. (2004). Márgenes de comercialización y concentración industrial en el mercado de frutas y hortalizas en Chile. Agroalimentaria, 9(18), 75-86. http://ve.scielo.org/scielo.php?script=sci_arttext\&pid $=$ S1316-03542004000100006

Valerio, D., García, A., Perea, J., Acero, R., \& Gómez, G. (2009). Caracterización social y comercial de los sistemas ovinos y caprinos de la región noroeste de República Dominicana. Interciencia, 34(9), 637-644. https://www.interciencia.net/ wp-content/uploads/2018/01/637-PEREA-1-8.pdf

Vázquez-Martínez, I., Vargas-López, S., Zaragoza-Ramírez, J. L., Bustamante-González, A, Calderón-Sánchez, F., RojasÁlvarez, J., \& Casiano-Ventura, M. A. (2009). Tipología de las explotaciones ovinas en la sierra norte del estado de Puebla. Técnica Pecuaria en México, 47(4), 357-369. https://colpospuebla.mx/documentos/productividad/ articulos/2009\%201.Vazquez\%20Martinez.\%20I.\%20Et\%20al.\%202009\%20-\%20M\%20-\%20Bustamante.pdf 